\title{
The Ponseti Method Followed by Minimally Invasive Surgery as Method of Choice in Treatment of Congenital Talipes Equinovarus: Review Article
}

\author{
Sinisa Ducic, Mikan Lazovic, Vladimir Radlovic, Bojan Bukva \\ University Children’s Hospital, Belgrade, Serbia
}

Correspondence: Tel.: + 381112060 602; Fax.: + 381112060651

Received: May 16, 2020; Accepted: November 3, 2020

\begin{abstract}
The objective of the study was to evaluate minimally invasive methods in treatment of congenital clubfoot. Congenital talipes equinovarus (CTEV), or clubfoot, is the most common congenital foot deformity, occurring in 1 to 2 in 1000 live births. CTEV etiology is not yet completely clear. Essentially, the deformity is the result of an intrauterine dislocation of the joints between the talus, calcaneus, navicular and cuboid bone and it includes four components: cavus, adductus, varus and equinus (CAVE). The diagnosis is made by a clinical examination and foot radiography. The treatment is based on the repositioning of the dislocated joints. There are different treatment modalities available, from conservative to exclusively surgical CTEV treatment. The Ponseti method is a primarily conservative treatment method using corrective long-leg casts, sometimes associated with minimal surgical intervention - Achilles tenotomy, followed by the use of an abduction brace. If needed, less invasive surgery ("a la carte") might be used to correct uncorrected components of CTEV. Based on the reports published from 2010 to 2020, as retrieved from databases (PubMed, Medline, Scopus), pertaining mostly to conservative treatment methods and primarily to the Ponseti method and based on the comparison between the Ponseti method and surgical methods of treatment, as well as other conservative methods of treatment, it can be concluded that the Ponseti method is the method of choice for the treatment of congenital CTEV in children today. Conclusion - The Ponseti treatment method, if used on time, fulfills all requirements that are expected from a contemporary medical procedure: simplicity in performance, minimally invasive, wide availability, cost effectiveness and successful treatment results.
\end{abstract}

Key Words: Talipes equinovarus • Ponseti method • Children.

\section{Introduction}

Talipes equinovarus (TEV), or clubfoot, is the most common congenital foot deformity, occurring in 1 to 2 in 1000 live births. In terms of gender distribution, the male-to-female ratio is 2.5:1 (1). Family history of the deformity is present in $24.4 \%$ of cases, and the deformity is bilateral in $50 \%$ of the patients $(2,3)$. The deformity occurs due to an intrauterine dislocation of the joints between the talus, calcaneus, navicular and cuboid bone, with the concave surfaces of the joints formed by the navicular, cuboid and heel bone rotating, i.e. luxating around the head of the talus inward and down- ward. The deformity itself is complex and involves at least four components: equinus (forefoot points downward), varus (heel is turned inward), adductus (forefoot is turned inward) and cavus (caved foot, or high arch) (4) (Fig. 1).

In addition, the lower leg is always hypotrophic and rotated inward and all structures of the foot are altered: bones, muscles, tendons, ligaments, joint capsules, blood vessels, nerves and skin. Treatment is based on the repositioning of the dislocated joints, following previous stretching or resection of the shortened structures. There are different treatment modalities available, from conservative to exclusively surgical CTEV treatment. Treatment 


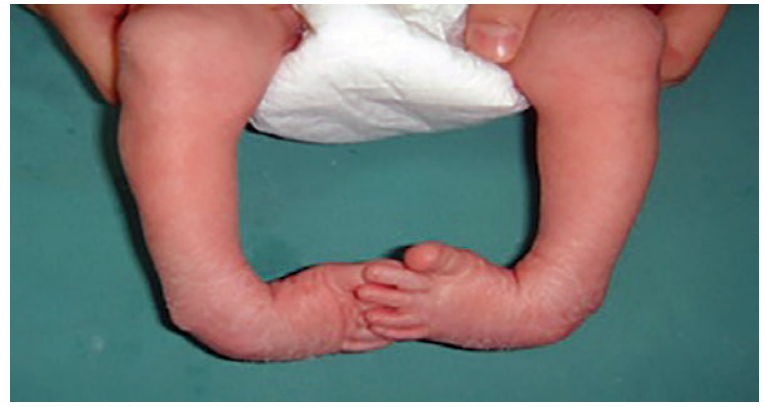

Fig. 1. Bilateral Talipes Equinovarus.

objective is to provide satisfactory correction in the long-term, with full, asymptomatic function of the foot and its acceptable appearance. The Ponseti method is a prominent contemporary method of CTEV treatment, which is a primarily conservative treatment method using corrective long-leg casting, sometimes with a minimal surgical intervention Achilles tenotomy, followed by application of an abduction orthosis (brace) $(4,5)$.

Aim of this review is to evaluate minimally invasive methods of surgery in treatment of congenital clubfoot in last ten years, especially after Ponseti method as the most common used method of treatment.

\section{Talipes Equinovarus Etiology}

Since clubfoot is frequently associated with neuromuscular diseases, one of the theories on its etiology is that it is a neuromuscular disorder. On the other hand, CTEV frequently presents as an isolated bone-muscular disorder in an otherwise healthy infant. The most prominent theory on CTEV etiology is that it is a disorder in the intrauterine lower leg and foot development, in the period from week six to week eight of gestation. In the last two decades, several other theories on CTEV etiology have emerged, such as: vascular deficiency, i.e. hypoplasia of the anterior tibial artery or absence of the dorsalis pedis artery, abnormal muscle insertion, environmental factors, increased maternal homocysteine levels, abnormal medial ligament myofibroblastic tissue etc. $(6,7,8,9)$. With the expansion of human genetics, new theories on TEV etiology emerged $(10,11)$. However, to this date, exact CTEV etiology remains unknown.

\section{Pathological Anatomy of the Clubfoot}

Knowledge of anatomic clubfoot pathology plays an important role in therapeutic principles. Displacement of the navicular, cuboid and heel bone around the head of the talus, as well as contracture of soft tissues (ligaments, joint capsules and tendons) form the basis of the clinical picture of foot equinovarus. In mid-20th century, Ponseti described CTEV and its components in detail, providing recommendations for its treatment (12). The dominant pathological anatomic feature is a deformity of the talus, consisting of an internal, plantar deviation of the anterior segment with a short talus neck orientated towards the midline, and a small talus body dislocated from the ankle. The angle between the neck and the body of the talus is altered: instead of the normal angle of 150 160 degrees, it is barely 90 degrees (4). This means that the joint surface of the head of the talus and the talus body are so close, as if the neck of the talus were almost inexistent. The navicular is displaced medially and plantarly, with a frequent false joint with medial malleolus. The medial displacement of the navicular exposes the cartilage of the head of the talus on the lateral aspect. The cuboid is also displaced medially, compared to the anterior part of the talus. Since the calcaneus is also medially rotated, all this leads to midfoot varus and adductus. The lower leg is usually hypotrophic and the entire talus rotated inward in the transversal plane $(4,5)$.

\section{Talipes Equinovarus Diagnosis}

Routine diagnostics of congenital clubfoot is based on patient history, i.e. the information that the deformity was present at birth and, in some cases, positive family history, on clinical examination and foot radiography. The clinical picture is specific: the foot is lumpy, pointing in the plantar direction; the heel is small, raised and rotated under the talus in an inverted position. There is a deep skin fold on 
the inside of the ankle. The midfoot and forefoot are adducted, inverted and rotated inward (4, 5, 12). On the outside of the foot, the skin is stretched and the head of the talus can be palpated underneath it. Passive correction is not completely possible and it reveals a tight, shortened tendon of the $\mathrm{m}$. triceps surae. The tendons of $\mathrm{m}$. tibialis posterior, $\mathrm{m}$. flexor digitorum longus and $\mathrm{m}$. flexor hallucis longus are also shortened, as are the plantar fascia and capsule, as well as the ligament structures in the midfoot and the hindfoot. Lower leg muscle hypotrophy is always present and both the lower leg muscles and the foot are shortened $(8,9)$.

Clubfoot grading (classification) is based on assessing the severity of each of its components and is an important predictive factor of treatment outcome. The Dimeglio classification system (Fig. 2) is generally used and is applicable until the age of $2(13,14)$.

In differential diagnosis, positional talipes equinovarus, arising in utero, as well as different forms of acquired equinovarus, should be considered. In clinical terms, postural CTEV resembles the congenital CTEV; however, the foot is of normal size, there is no lower leg hypotrophy and manual correction is highly successful. Radiographic findings are

A

B normal. The prognosis is good. Clubfoot can be associated with multiple generalized development Assessment of Clubfoot by Severity

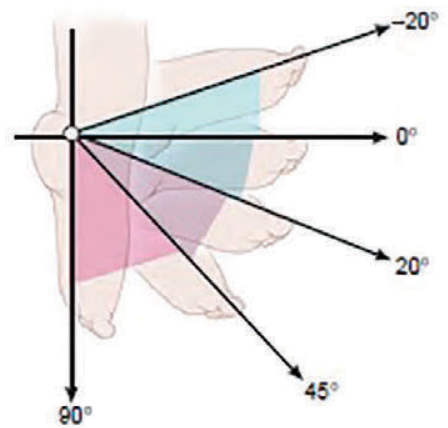

Sagittal plane evaluation of equinus

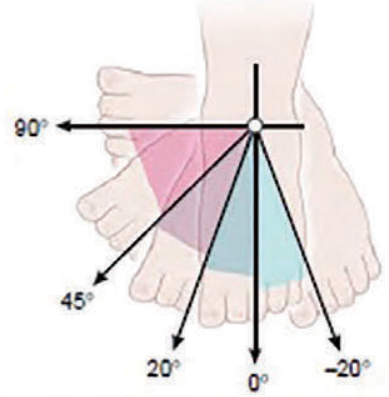

Horizontal plane evaluation of derotation of the calcaneopedal block

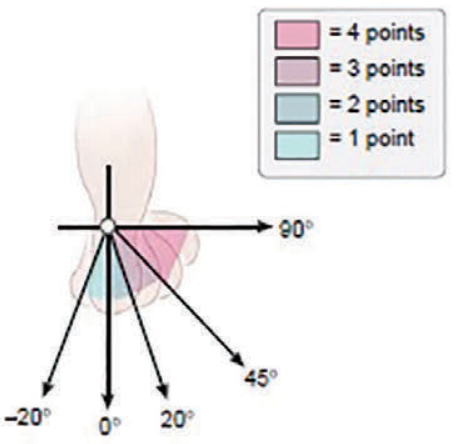

Frontal plane evaluation of varus

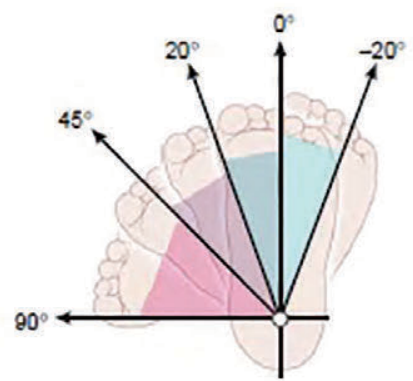

Horizontal plane evaluation of forefoot relative to hindfoot

\begin{tabular}{|c|c|c|c|}
\hline Reducibility & Points & Other parameters & Points \\
\hline $80^{\circ}$ to $45^{\circ}$ & 4 & Posterior crease & 1 \\
\hline $45^{\circ}$ to $20^{\circ}$ & 3 & Medial crease & 1 \\
\hline $20^{\circ}$ to $0^{\circ}$ & 2 & Cavus & 1 \\
\hline$<0^{\circ}$ to $-20^{\circ}$ & 1 & Poor muscle condition & 1 \\
\hline
\end{tabular}

\begin{tabular}{|c|l|c|c|}
\hline Classification grade & Type & Frequency (\%) & Score \\
\hline I & Benign & 20 & $(<5)$ \\
II & Moderate & 33 & $(=5<10)$ \\
III & Severe & 35 & $(=10<15)$ \\
IN & Very severe & 12 & $(=15<20)$ \\
\hline
\end{tabular}

Fig. 2. Classification of clubfoot according to Dimeglio. A. Assessment of clubfoot by severity. Each major component of clubfoot (equinus, heel varus, medial rotation of the calcaneo-pedal "block," and forefoot adductus) is graded clinically from 4 to 1 (most severe to most mild). Additional points are added for deep posterior and medial creases, cavus, and poor muscle function. B. Classification of clubfoot. The total score is stratified into four groups of severity (benign to very severe, grades I to IV). From Herring JA et al. Tachdijans pediatric orthopaedics, 5th ed. p. 921. Elsevier Saunders, 2014. 
syndromes and conditions, of which spinal dysraphism and congenital arthrogryposis are the most common. For this reason, each child presenting with CTEV should be carefully examined, not just in terms of other limb joints but overall, as a form of screening for potential congenital anomalies.

\section{Foot Radiography}

Radiography in diagnosis of CTEV is not essential. The purpose of radiography is to define the anatomic relations and the degree of subluxation of the talus-calcaneus-navicular joints. The most commonly used projections are antero-posterior (AP) and lateral view projections, with the foot placed in the maximally corrected position (5). On the AP view, the talocalcaneal angle is formed by the ossification centres of the talus and the calcaneus. In a healthy foot, the base of the talus aligns with the first, while the axis of the calcaneus aligns with the fifth metatarsal bone, closing a 20 to 40-degree angle; in CTEV, as the heel inverts, the talocalcaneal angle closes and approaches zero. In a lateral view, in normal foot it ranges from 35 to 50 degrees, and in CTEV it is decreased. Echosonography is occasionally used to precisely define the anatomy; it is useful for diagnosis already in utero, from week 16 (15). In addition, computerized tomography, arthrography and NMR of the foot can also occasionally be used.

\section{Clubfoot Treatment}

The treatment is based on repositioning of the dislocated joints, after stretching or resection of the shortened structures (muscles, tendons, ligaments). It is important to stress that treatment should begin as early as possible, optimally in the first three weeks after birth, while the deformity is relatively correctable. The mother's estrogen makes the soft structures of the foot easier to correct, until it is cleared from the infant's body. The purpose of treatment is to achieve a foot that is pain-free, mobile, looks as close to normal as possible and requires no special footwear. There are different treatment modalities avail- able, from conservative to exclusively surgical CTEV treatment. The contemporary trend in the treatment of congenital CTEV is conservative treatment, or minimally invasive surgical procedure $(16,17)$.

Bensahel (18) advocated a non-surgical CTEV treatment method based on physical medicine procedures that stretch the shortened connective structures, after which the foot is placed in a device and then fitted with a brace. The treatment begins in the child's second week. Treatment procedures comprise 30-minute physical therapy sessions, after which the foot is placed in a device that passively stretches the shortened structures for 8 hours per day. Subsequently, a so-called "splint" is fitted to the foot, to keep it in the maximally corrected position until the next treatment session on the following day (19). What makes this method difficult to implement is non-compliance: in a study of 216 affected feet, Dimeglio et al. found that as many as $32 \%$ of the patients failed to complete the treatment course using this method, because the parents found it difficult to comply with the treatment (20). Johnson and Richards designed a non-surgical treatment method for CTEV at the beginning of the 21 st century, which was named the "French technique" $(21,22,23)$. The method is based on correcting the deformity using adhesive tape, which achieves the necessary correction; subsequently, the correction is maintained using short-leg casts and, if necessary, minimal surgical interventions (23, 24). Alvarez et al. provided an interesting approach to treating the congenital TEV: they injected botox (Botulinum toxin type A) into the shortened muscles - the gastrocnemius, soleus and tibialis posterior achieving satisfactory results in the period immediately after the intervention. This method was then used by Johnson and Richard as an addition to the French treatment method, initially injecting botox into the shortened muscle structures which were then corrected using adhesive tape and short-leg casts $(25,26,27)$.

In mid 1940-ies, Ignacio Ponseti began the development of one of the non-surgical equinovarus treatment methods that has been perfected over the years and is now widely used. The Ponseti treat- 
ment method encompasses successive use of longleg casts in different positions (Fig. 3) to correct the different components of TEV: cavus, adductus, varus and equinus (CAVE) over a period of 6 weeks, with casts being replaced weekly, with or without achillotenotomy $(28,29,30)$. Just prior to casting, ligaments and other soft structures are passively stretched for 1 to 3 minutes $(5,29)$.

Treatment begins with the correction of cavus, which is achieved by supination of the forefoot and maintaining that position for casting. Cavus is usually completely corrected with the first cast. (29, $30,31)$ After the cavus is corrected, adductus and varus are corrected simultaneously. Before casting, the defect is manually corrected for up to 3 minutes by abducting the foot at the level of the tarsus and metatarsus. This correction is performed at three points, while maintaining the previously achieved cavus correction. When applying this manoeuvre, the objective is to achieve a normal anatomic correlation between the foot joints, primarily the talonavicular and calcaneocuboid joints. Adductus and metatarsus varus are corrected while the foot is in equinus position, to achieve the physiological anatomic position between the talus and the calcaneus, where the calcaneus will spontaneously fit into place under the talus during the manipulation. It takes three to four weeks of successive corrections, with immobilization by casting, to correct foot adductus and varus. With each change of the cast, foot supination is gradually decreased with the purpose to correct the inversion of the tarsal bones and to achieve foot abduction $(31,32,33)$.

The remaining foot equinus is the last component of the equinovarus to be corrected. The correction begins with the foot in valgus and abduction of about 70 degrees, to prevent a relapse of the previously corrected deformity. The foot is gradually dorsiflexed towards the shin and fixed in the achieved position with a cast. During dorsiflexion, pressure is applied to the entire foot. Equinus can be corrected with the progressive correction and replacement of casts at each stage. $(31,32,33)$ In those equinovarus cases where equinus cannot be corrected by manipulation and casting, Achilles te- notomy is performed $(17,34)$. It is safe to do a tenotomy up to one year of age, in local or general anaesthesia. Many authors perform achilles tenotomy under general anaesthesia, especially in patients older than three months of age, to facilitate casting and complete correction of the deformity $(17,34$, 35). Following Achilles tenotomy, a cast is worn for three to four weeks.

Once the last cast is removed, 3-4 weeks after Achilles tenotomy, a brace comprised of a metal bar (static or dynamic) with attached leather lace-up boots, is used. For unilateral CTEV cases, the brace is positioned so that the feet are placed shoulderwidth apart on the metal bar, with the affected foot abducted to about 60-70 degrees and the healthy foot positioned at about 30-40 degrees $(34,35)$. Dorsiflexion is at about 10 degrees. In the first 3 months, the brace is worn 24 hours per day, i.e. day and night. After this period, the child wears the brace all night and 2-4 hours during the day, i.e. 14 to 16 hours per day (sleep time), until 3-4 years of age $(34,35,36)$.

Wearing the brace is an essential part of the treatment procedure, necessary to maintain the results of the casting and minimal surgical interventions $(36,37)$. Various types of brace are used: the most common Dennis-Brown, Dalas-Ponseti and Steenback foot abduction orthosis are used (38).

Many current studies report extremely good success rates of the Ponseti method in the treatment of CTEV (39). Some authors report up to $100 \%$ success rate $(40)$. However, to maintain the achieved correction, it is of critical importance that the child wears the abduction brace, at least at the age of four (41).

Despite the efforts to treat CTEV conservatively, sometimes this proves impossible and one of the surgical methods of treatment must be employed. When it comes to surgical foot treatment, it must be stressed that each foot is different, and that the clinical examination is the corner stone of any surgical plan. This means that only the component(s) of CTEV that cannot be resolved conservatively should be treated surgically. The most common surgical procedure is transfer of tibialis anterior to 

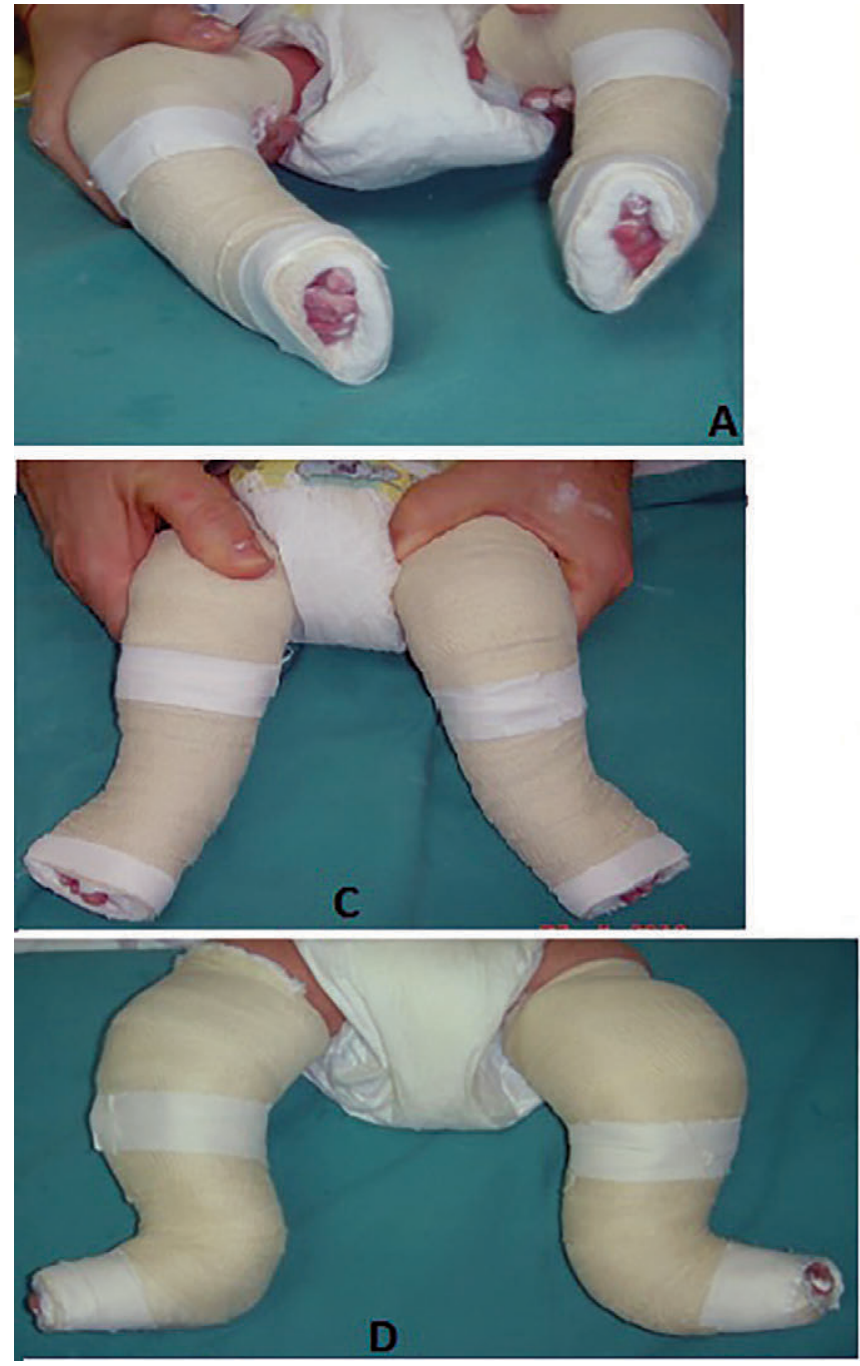

Fig. 3. Ponseti Casts. A=Cavus Correction Cast; $B, C=$ Matatarsus and Aductus Correction Cast; $D, E=E q u i n u s$ Correction Cast.

lateral cuneiform or cuboid bone (after age of two), which is essentialy part of Ponseti method (35). Also, quite common is an equinus reccurence or relapse, even after Achilles tenotomy. According to Siapkara et al. only division of fibrous the posterolateral knot after Achilles re-tenotomy, which includes the tissues deep to the peroneal tendons, allowed correction of the talus so the capsule of the ankle joint or sectioning of the posterior talofibular ligamenthas to be done to correct equinus (42).

Most surgeons believe that the optimal age for a surgical intervention is between age 3 to 6 months, due to the great potential for foot remodelling ( 35 ,
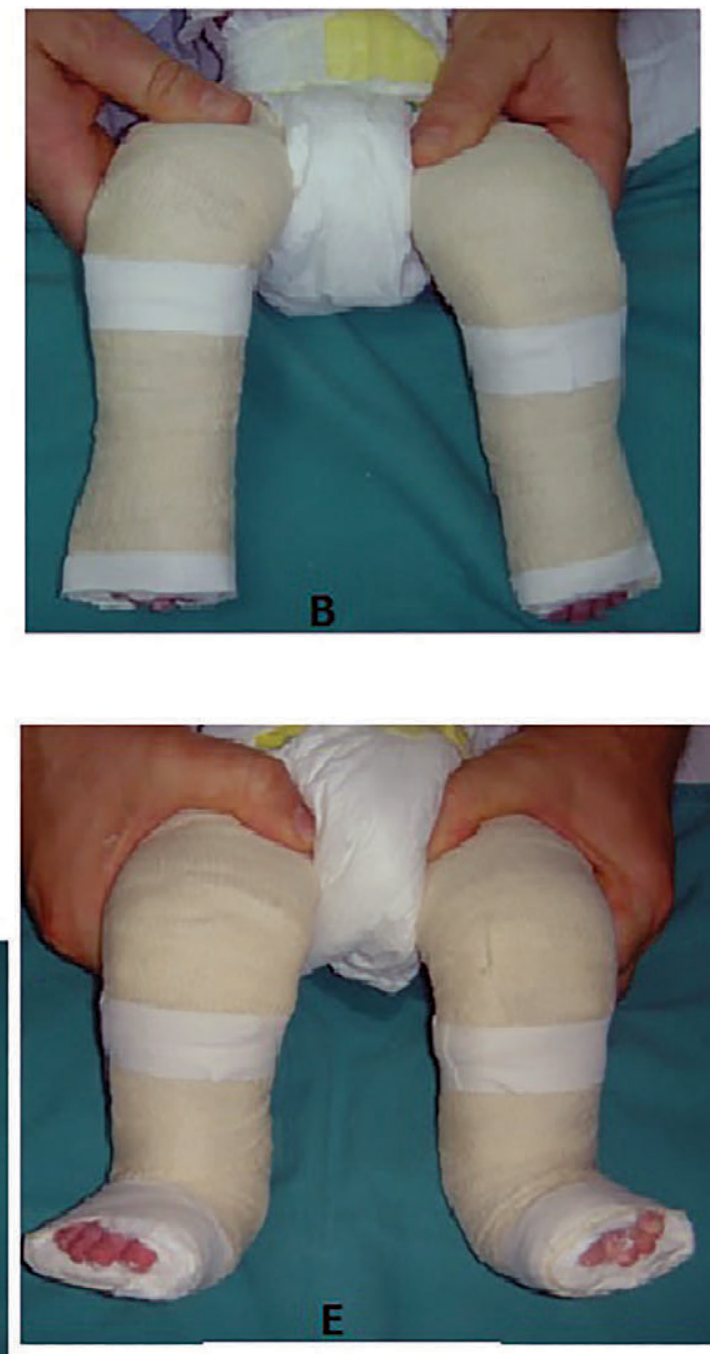

39, 41). The principle of surgical clubfoot treatment relies on dissecting or lengthening the soft tissue structures in the foot that are shortened, on anatomic repositioning and fixation of the foot in its correct, anatomic position using osteosynthetic materials. There are many surgical techniques aimed at resolving CTEV, and the selection of the appropriate one will depend on the degree of deformity, age of the child and experience of the surgeon (Table 1) $(41,43)$.

It is the current thinking that brace wearing is critical to maintain the correction achieved by manipulation and casting. To minimize relapse, it is 


\section{Table 1. Surgical Technics Used in Club Foot Tretment}

\begin{tabular}{|c|c|c|}
\hline Patient age & Treatment procedure & Treatment method \\
\hline \multirow{3}{*}{6 months to 2 years } & 1 & Soft tissue release \\
\hline & 2 & In case the plantar arch increases, plantar aponeurosis should be resected \\
\hline & 3 & $\begin{array}{l}\text { If the adductus is not corrected, naviculocuneiform joint and cuneiform-metatarsal joint } \\
\text { capsulotomy should be performed }\end{array}$ \\
\hline 2 to 4 years & 4 & $\begin{array}{l}\text { If the forefoot has not been corrected after steps 1, } 2 \text { and 3, calcaneocuboid joint cartilage } \\
\text { should be excised }\end{array}$ \\
\hline \multirow{9}{*}{4 to 8 years } & 5 & $\begin{array}{l}\text { If forefoot adductus has not been corrected after steps } 1,2,3 \text { and } 4 \text {, one of the following } \\
\text { procedures should be performed: }\end{array}$ \\
\hline & $5 \mathrm{~A}$ & Fusion of the calcaneocuboid joint (Dilwyn-Evans procedure) \\
\hline & $5 \mathrm{~B}$ & Excision of the distal end of the calcaneus (Lichtblau procedure) \\
\hline & $5 \mathrm{C}$ & Decancellation of the cuboid \\
\hline & $5 \mathrm{D}$ & First cuneiform bone osteotomy \\
\hline & $5 \mathrm{E}$ & Tarsometatarsal osteotomy \\
\hline & $5 \mathrm{~F}$ & Metatarsal osteotomy for children over the age of 5 \\
\hline & 6 & $\begin{array}{l}\text { In case of a weak peroneus and a strong } \mathrm{m} \text {. tibialis anterior, } \mathrm{m} \text {. tibialis anterior tendon } \\
\text { transposition should be performed additionally }\end{array}$ \\
\hline & 7 & $\begin{array}{l}\text { In case of an uncorrected heel varus, heel bone osteotomy (Dwyer) should be performed } \\
\text { additionally }\end{array}$ \\
\hline \multirow{2}{*}{8 to 10 years } & 8 & Midtarsal osteotomy for persistent cavus \\
\hline & 9 & Distraction osteogenesis (Ilizarov) \\
\hline Over 10 years of age & 10 & Triple arthrodesis \\
\hline
\end{tabular}

essential to identify the high-risk patients, and the preventive measure is implied. It was recently demonstrated that brace noncompliance was the main factor relating to the relapse (38). Walking cast or lower leg orthosis (LLO) are widely used to prevent relapses of CTEV (44). The most common used is Berger's lower leg orthosis. The principals of walking cast and LLO are similar: fixation of subtalar joint in valgus position by encasing the calcaneopedal unit, which is then everted in the subtalar joint and locking after applying heel cap. It results in hindfoot valgus about 10-15 degrees (45). Also, we externally rotated the foot (approximately in 20 degrees) against the knee joint line 40 degrees (45). Rotational stability of the orthosis in relation to knee axis is crutial to correct the foot. The knee motion are not limited and children are able to kick and walk. Also, very importatnt key point is that CTEV has to be followed up to maturity.

\section{Conclusion}

Surgeons have contested for years to determine the method of choice for the treatment of congenital CTEV. In the last decade, the heated debate has subsided with the expansion of the Ponseti's method of non-surgical treatment. Minimally surgical techniques should only be used if the conservative treatment fails. The Ponseti treatment method, if used in time, provides all that contemporary medicine requires a treatment procedure to provide: simplicity in performance, minimal invasiveness, wide availability, cost effectiveness and successful treatment results.

Conflict of Interest: The authors declare that they have no conflict of interest. 


\section{References}

1. Smythe T, Kuper H, Macleod D, Foster A, Lavy C. Birth prevalence of congenital talipes equinovarus in low- and middle-income countries: a systematic review and metaanalysis. Tropical Med Int Health. 2017;22(3):269-85.

2. Gray K, Barnes E, Gibbons P, Little D, Burns J. Unilateral versus bilateral clubfoot: an analysis of severity and correlation. J Pediatr Orthop B. 2014;23:397-9.

3. Agarwal A, Agrawal N, Barik S, Gupta N. Are bilateral idiopathic clubfeet more severe than unilateral feet? A severity and treatment analysis. J Orthop Surg (Hong Kong) 2018;26(2):230.

4. Herring JA, Adams RC, Anderson ME, Birch JG, Cherkashin A, Copley LA et al. Tachdijans pediatric orthopaedics, 5th ed. p.786-780.Elsevier Saunders, 2014.

5. Balasankar G, Luximon A, Al-Jumaily A.l. Current conservative management and classification of club foot: A review. J Pediatr Rehabil Med. 2016; 9(4):257-64.

6. Bacino CA, Hecht JT. Etiopathogenesis of equinovarus foot malformations. Eur J Med Genet 2014;57:473-9.

7. Lovell ME, Morcuende JA. Neuromuscular disease as the cause of late clubfoot relapses: report of 4 cases. Iowa Orthop J 2007;27:82-4.

8. Lis A, de Castro C, Nordin M. Biomechanics of tendons and ligaments. In: Nordin M, Frankel VH, eds. Basic Biomechanics of the Musculoskeletal System. Fourth ed. Baltimore: Wolters Kluwer/Lippincott Williams \& Wilkins, 2012.

9. Özkaya N, Nordin M, Goldsheyder D, Leger D. Fundamentals of Biomechanics: Equilibrium, Motion, and Deformation. Third ed. New York: Springer. 2012;221-36.

10. Dobbs MB, Gurnett CA. Genetics of clubfoot. J Pediatr Orthop B. 2012;21:7-9.

11. Lu W, Bacino CA, Richards BS, Alvarez C, VanderMeer JE, Vella $\mathrm{M}$ et al. Studies of TBX4 and chromosome 17q23.1q23.2: an uncommon cause of nonsyndromic clubfoot. Am J Med Genet. 2014; A 158A:1620

12. Ponseti IV. Congenital clubfoot. Fundamentals for treatment. Oxford: Oxford University Press. 1996; p. 55.

13. Diméglio A, Bensahel H, Souchet P, Mazeau P, Bonnet F. Classification of clubfoot. J Pediatr Orthop. 1995;4:129-36.

14. Brazell, Chris BA, Jones A, Baschal R, Miller N, Holmes KS et al. Dimeglio Score Predicts Treatment Difficulty During Ponseti Casting for Isolated Clubfoot. Journal of Pediatric Orthopaedics. 2019;39(5):402-5.

15. Society for Maternal-Fetal Medicine, McKinney J, Rac MWF, Gandhi M. Congenital talipes equinovarus (clubfoot). Am J Obstet Gynecol. 2019;221(6):B10-B12.
16. Gottschalk HP, Karol LA, Jeans KA. Gait analysis of children treated for moderate clubfoot with physical therapy versus the Ponseti cast technique, J Pediatr Orthop. 2010;30:235

17. Richards BS: Ponseti clubfoot treatment - limited surgery is often required for successful outcomes at a minimum 5 year follow up. CHAPTER 23 Disorders of the Foot 864. e7 In Pediatric Orthopaedic Society of North America annual meeting. Montreal, Quebec, 2011.

18. Bensahel H, Bienayme B, Jehanno P. History of the functional method for conservative treatment of clubfoot. J Child Orthop. 2007;1(3):175-6.

19. Johnston W, Richards BS. Non-operative treatment of clubfoot-the French technique. In: Proceeding of the Pediatric Orthopaedic Society of North America, Annual Meeting; 1999 May 15-9; Lake Buena Vista, Florida. P 25.

20. Dimeglio A, Bonnet F, Mazeau P, De Rosa V. Orthopaedic treatment and passive motion machine: consequences for the surgical treatment of clubfoot. J Pediatr Orthop B. 1996; 5:173-80.

21. Zanardi A, Fortini V, Abati CN, Bettuzzi C, Salvatori G, Prato $\mathrm{E}$ et al. Standing and walking age in children with idiopathic clubfoot: French physiotherapy versus Ponseti method. J Child Orthop. 2019; 13(5):471-7.

22. Dimeglio A, Canavese F. The French functional physical therapy method for the treatment of congenital clubfoot. J Pediatr Orthop B. 2012;21:28-39.

23. Chotel F, Parot R, Seringe R, Berard J, Wicart P. Comparative study: ponseti method versus French physiotherapy for initial treatment of idiopathic clubfoot deformity. J Pediatr Orthop 2011;31:320-5.

24. He JP, Shao JF, Hao Y. Comparison of different conservative treatments for idiopathic clubfoot: Ponseti's versus non-Ponseti's methods. J Int Med Res. 2017;45(3):1190-9.

25. Alvarez CM, De Vera MA, Chhina H, Williams L, Durlacher K, Kaga S. The use of botulinum type A toxin in the treatment of idiopathic clubfoot: 5-year follow-up. J Pediatr Orthop. 2009;29(6):570-5.

26. Ganesan B, Luximon A, Al-Jumaily A, Balasankar SK, Naik GR. Ponseti method in the management of clubfoot under 2 years of age: A systematic review. PLoS One. 2017;12(6):e0178299.

27. Alvarez CM, Wright JG, Chhina H, Howren A, Law P. Botulinum Toxin Type A Versus Placebo for Idiopathic Clubfoot: A Two-Center, Double-Blind, Randomized Controlled Trial. J Bone Joint Surg Am. 2018;100(18):1589-96.

28. Švehlík M, Floh U, Steinwender G, Sperl M, Novak M, Kraus T. Ponseti method is superior to surgical treatment 
in clubfoot - Long-term, randomized, prospective trial. Gait Posture. 2017;58:346-51.

29. Ponseti IV. The treatment of congenital clubfoot. J Orthop Sports Phys Ther. 1994;20(1):1.

30. Narasimhan R, Panda AK, John R. A retrospective study of idiopathic clubfoot managed by Ponseti method using Pirani and Dimeglio scoring, in Indian population: a minimum 3-year follow-up. J Pediatr Orthop B. 2021;30(1):7179. doi: 10.1097/BPB.0000000000000728.

31. Zhang G, Zhang Y, Li M. A Modified Ponseti Method for the Treatment of Rigid Idiopathic Congenital Clubfoot. J Foot Ankle Surg. 2019; 58(6):1192-6.

32. Elgohary HS, Abulsaad M. Traditional and accelerated Ponseti technique: a comparative study. Eur J Orthop Surg Traumatol. 2015;25:949-53.

33. Xu RJ. A modified Ponseti method for the treatment of idiopathic clubfoot: a preliminary report. J Pediatr Orthop. 2011;31:317-9.

34. Cohen E, Katz T, Rozen U, Friesem T, Leibovitz E. The Influence of Achilles Tenotomy and Compliance with Foot Abduction Orthosis on the Relapse Rate of Ponseti Treatment for Idiopathic Clubfoot: A Regional Study. J Foot Ankle Surg. 2020;59(4):784-787. doi: 10.1053/j. jfas.2019.12.007

35. Ponseti IV. Treatment of the complex idiopathic clubfoot. Clin Orthop Relat Res. 2006;451:171-6.

36. Ramírez N, Flynn JM, Fernández S, Seda W, Macchiavelli RE. Orthosis noncompliance after the Ponseti method for the treatment of idiopathic clubfeet: a relevant problem that needs reevaluation. J Pediatr Orthop. 2011;31:710.

37. Zionts LE, Dietz FR: Bracing following correction of idiopathic clubfoot using the Ponseti method. J Am Acad Orthop Surg. 2010;18:486.
38. Zhao D, Li H, Zhao L, Kuo KN, Yang X, Wu Z, Liu J, Zhu J. Prognosticating Factors of Relapse in Clubfoot Management by Ponseti Method. J Pediatr Orthop. 2018;38(10):51420. doi: 10.1097/BPO.0000000000000870.

39. Smythe T, Chandramohan D, Bruce J, Kuper H, Lavy C, Foster A. Results of clubfoot treatment after manipulation and casting using the Ponseti method: experience in Harare, Zimbabwe. Tropical Med Int Health. 2016;21(10):1311-8

40. Sinha A, Mehtani A, Sud A, Vijay V, Kumar N, Prakash J. Evaluation of Ponseti method in neglected clubfoot. Indian J Orthop. 2016;50(5):529-35.

41. Zhao D, Liu J, Zhao L, Wu Z. Relapse of clubfoot after treatment with the Ponseti method and the function of the foot abduction orthosis. Clin Orthop Surg. 2014;6:245-52.

42. SiapkaraA, Duncan R. Congenital talipes equinovarus: a review of current management. J Bone Joint Surg Br. 2007;89(8):9951000. doi: 10.1302/0301-620X.89B8.19008.

43. Eidelman M, Kotlarsky P, Herzenberg JE. Treatment of relapsed, residual and neglected clubfoot: adjunctive surgery. J Child Orthop. 2019;13(3):293-303.

44. Desai L, Oprescu F, DiMeo A, Morcuende JA. Bracing in the treatment of children with clubfoot: past, present, and future. Iowa Orthop J. 2010;30:15-23.

45. Berger N, Lewens D, Salzmann M, Hapfelmeier A, Döderlein L, Prodinger PM. Is unilateral lower leg orthosis with a circular foot unit in the treatment of idiopathic clubfeet a reasonable bracing alternative in the Ponseti method? Five-year results of a supraregional paediatric-orthopaedic centre. BMC Musculoskelet Disord. 2018;18;19(1):229. doi: 10.1186/s12891-018-2160-1. 